\title{
Comparative Study on Various Custom Devices
}

\author{
Uzma Aslam ${ }^{1}$, Faizan Arif Khan², Prabhat Ranjan Sarkar ${ }^{3}$, Abu Shoban ${ }^{4}$ \\ M.Tech Student, Dept. of EEE, Integral University, Lucknow India ${ }^{1,4}$ \\ Assistant Prof, Dept. of EEE, Integral University, Lucknow India ${ }^{2,3}$
}

\begin{abstract}
This paper gives emphasis on comparative study of compensating devices used for power quality improvement. In distribution system, power quality problem has become a big issue in recent years. Lack of power quality affects consumers in many ways such as transients, short duration voltage variation, long duration voltage variation, voltage imbalance, waveform distortion etc.The power quality improvement is mandatory for the newer sensitive to power quality disturbances especially with interruptions, harmonics and voltage sags. These problems are offered flexible solutions by custom power. The custom power devices can be divided into two categories - network reconfiguring type and compensating type. SVC, STATCOM, IPC, DVR, UPFC, TCSC, TCPST and DSTATCOM are the different types of FACT devices which can be used to solve these types of problems.
\end{abstract}

Keywords: Power quality improvement, Harmonics and Interruption, Custom power, FACT devices.

\section{INTRODUCTION}

The two most important aspects of any power delivery system are Reliability and quality. The term 'Power Quality' is often described as maintaining near sinusoidal voltage at stipulated frequency of 50 or $60 \mathrm{~Hz}$. at the customer inlet points. The power quality problems are not new but customer awareness of these problems has increased. There are the sets of conventional solutions use passive elements and do not always respond correctly as the nature of the power conditions change. The custom power enhances the reliability and quality of power that is delivered to customers. Custom power provides an integrated solution to these problems which are faced by the utilities and power distributors [1] .The reliability of the power delivered can be improved in terms of reduced interruptions and reduced voltage variations through this technology. The proper use of this technology will benefit the entire commercial, industrial and domestic customers. The custom power devices are basically of two types network reconfiguring type and compensating type. The network configuring equipments are such as GTO TYPE or thyristor types which are usually used for fast current limiting and current breaking during faults.[2] The quality of supplied voltage is improved by compensating devices and also it compensate a load, i.e., correct its power factor, unbalance etc.

\section{POWER QUALITY ISSUES}

There are very sensitive loads such as hospitals (life support, operation theatre, and patient database system), processing plants such as semiconductor, fabric, rayon and food, and air traffic control, financial institutions and numerous other service providers and data processing that require clean and uninterrupted power. In some processes such as food processing plants, semiconductor manufacturing, a large amount of products can be ruined by a voltage dip of very short duration. The customers are very well aware of this type of dips because such interruption affect them a lot in financial prospective. Contactors on motor drives results in drop out by short dips. The conditions for quality control of the product can be destroyed by stoppage in a portion of a process and restarting of the production is required. Thus in this changed scenario in which the customers increasingly demand quality power, the term power quality (PQ) attains increased significance. Transmission lines are exposed to the forces of nature. Furthermore, each transmission line has its load ability limit that is often determined by either stability considerations or by thermal limits. [2] Even though the power quality problem is a distribution side problem, transmission lines often have an impact on the quality of power supplied.

\section{III.CUSTOM POWER CONCEPT}

The concept of custom power was introduced by N. G. Hingorani [3] which is based on the use of power electronic controllers in the distribution system to supply value-added, reliable, high quality power to its customers. For many customers it is a preferred alternative to the customer improvising utility power by their own means. Many utilities are looking forward in the direction of value-added Custom Power service to their large customers.

Custom Power means that the specified power quality from a utility is received by the customer or in coordination with the utility, at the fence equipment is installed by the customer which includes an acceptable combination of the following features:

\section{No (or rare) power interruptions.}

Magnitude and duration of voltage reductions within specified limits.

Magnitude and duration of over voltages within specified limits.

$\square$ Low harmonic voltage.

Low phase unbalance.

Acceptance of fluctuating, nonlinear and low power factor loads without significant effect on the terminal voltage. Custom power is a strategy, which is intended principally to convene the requirement of industrial and commercial consumers. The concept of the custom power 
is tools of application of power electronics controller devices into power distribution system to supply a quality of power, demanded by the sensitive users. These power electronics controller devices are also called custom power devices because through these valuable powers is applied to the customers. They have good performance at medium distribution levels and most are available as commercial products. The complete classification of custom power devices is shown in the figure 1

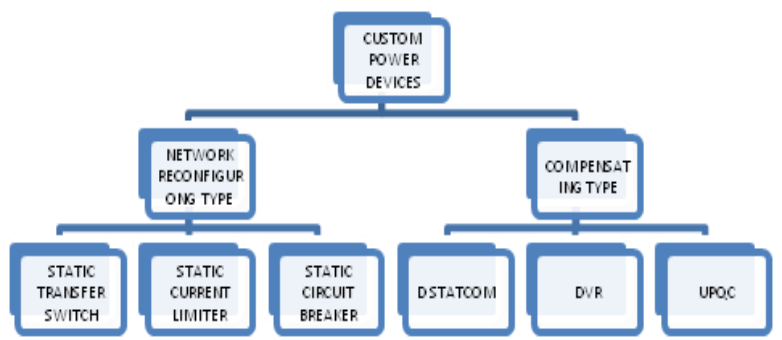

Fig.1 Block diagram of Custom Power Devices [1]

\section{NEED FOR CUSTOM POWER}

The ideal ac line supply by the utility system should be a pure sine wave of fundamental frequency $(50 / 60 \mathrm{~Hz})$. In addition, the peak of the voltage should be of rated value. Unfortunately the actual ac line supply that we receive everyday departs from the ideal specifications. Impulses, switching surges and over voltages which affect the insulation, would most likely result from lightning strikes and switching events in the transmission and distribution system. Voltage sags (also known as dips) can cause loss of production in automated processes since voltage sag can trip a motor or cause its controller to malfunction. For semiconductor manufacturing industries such a loss can be substantial. Voltage sag can also force a computer system or data processing system to crash. To prevent such a crash, an uninterruptible power supply (UPS) is often used, which, in turn, may generate harmonics. The protective circuit of an adjustable speed drive (ASD) can trip the system during a voltage swell. Also voltage swells can put stress on computers and many home appliances, thereby shortening their lives. A temporary interruption lasting a few seconds can cause a loss of production, erasing of computer data etc. The cost of such an interruption during peak hours can be hundreds of thousands of dollars. Harmonics would most likely be the consequence of high harmonics in the customer load, or the saturation of a utility's transformers. These harmonics would then be amplified by the natural resonances in the utility system and/or the customer system.

There are a number of reasons for the choice of the Custom Power concept for many customers and on a long term basis for most customers. These reasons are:

-The customers are better served if they receive a comprehensive solution to their power supply problems from the power supply service providers.

-Most of the voltage reductions and interruptions result from events that involve the utility system.

-In general, the total cost of the solutions that involve the utilities' own systems would be much less than the cost of solutions put in place by the individual customers.
- At least from the point of view of reliability, migration to the Custom Power concept seems to be inevitable

\section{COMPARATIVE STUDY OF CUSTOM POWER DEVICES}

The power electronic controllers that are used in the custom power solution can be network reconfiguring type or compensating type. The network reconfiguration devices are usually called switchgear and they include current limiting, current breaking and current transferring devices.[4]

The solid state or static versions of the devices are called

- Solid state current limiter (SSCL)

- Solid state breaker (SSB)

- Solid state transfer switch (SSTS)

Compensating devices are either connected in shunt or in series or a combination of both. The devices include

- Distribution STATCOM (DST ATCOM)

- Dynamic voltage restorer (DVR)

- Unified power quality conditioner (UPQC)

comparative study of custom power devices are done on the basis of following parameters as follows

\section{A. Static Current Limiter.}

Distribution systems current limiting devices are classified into two categories - single-shot devices and multi operation devices [1]. A typical single-shot device is a current limiting fuse. In addition to limiting fault currents, these devices can also break a faulted circuit. However, such a device needs human intervention for replacement once the fault is cleared. Multi-operation devices can be vacuum, semiconductor or superconductor type. The superconductor device operates through the quenching of the superconducting property at high magnetic fields. It is a series connecting devices that reduces fault current level by inserting series inductance in faulty path. It consists of pair of GTO with snubber circuit and inductor.

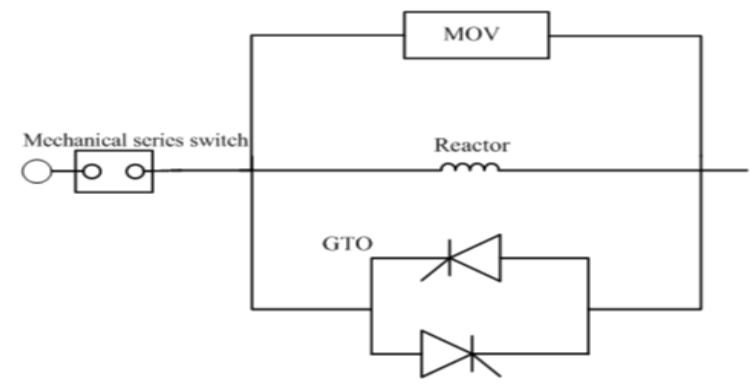

Fig.2 A GTO Based fault current limiter [4]

Current Limiter Topology:

The topology of a typical current limiter is shown in Figure 5. It contains an anti-parallel (back-to-back) gate turn-off thyristor (GTO) switch, a current limiting inductor and a zinc oxide $(\mathrm{ZnO})$ arrester, all connected in parallel $[2,3]$. The combination is connected in series with the distribution feeder that needs to be protected. The schematic diagram of the back-to-back GTO switch is shown in Figure 6.2. It includes a series of opposite poled GTO pairs, each of which has an RC snubber connected in 
parallel. The number of GTO switches depends on the rated peak voltage level across the current limiter. The $\mathrm{ZnO}$ arrester can limit this voltage level.It is to be noted that a GTO can be switched off at any time by applying a negative gate pulse. Therefore it has the capability to interrupt a current at any time. A thyristor, on the other hand, switches off only when the current through it changes polarity. The magnitude of the fault current will depend on the instant of the fault occurrence - the closer the fault to the zero crossing of the current; the more will be the magnitude of the current. If an anti-parallel thyristor switch is in a current limiter, it will keep on conducting till the next zero crossing irrespective of the occurrence of the fault. Since this will defeat the purpose for which a current limiter is installed, thyristor switches are not considered favorably for current limiter application.

\section{B. Static Transfer Switch.}

Static Transfer Switch (STS) is used to protect sensitive load voltage sag or swell. It is composed of two parallel connected Thyristor or GTO blocks. Each block consists of three GTO or thyristor corresponding to the three phase of the system. The common configuration of STS in distribution system is shown in Fig 2.

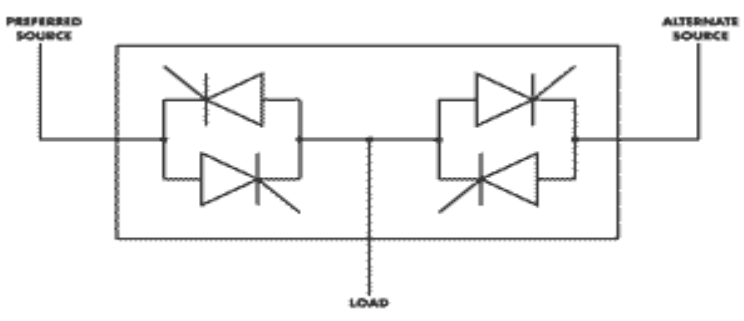

Fig.3 Static transfer switch [4]

\section{Solid State Breaker.}

The solid state breaker is based on the GTO or thyristor switching technology. It is a high- speed switching device, applied to reduces the electrical fault and protect from large current in distribution system. It can be used in a single switch, static transfer switch, hybrid switch or a low level fault interrupter. The voltage and current rating of the breaker describes the requirement of no. of switching devices, cost and the losses of the breaker. It perform auto reclosing function.

D. Uninterruptible Power Supply.

Uninterruptible power supply (UPS) is the conventional response to circumvent production interruption and outage costs. In UPS load has received the power from source via two stage operation: conversion $(\mathrm{ac} / \mathrm{dc})$ and inversion (dc/ac). During voltage dip or an interruption, the load voltage is made constant by energy, generated through battery. The performance of ups is depending on energy storage capacity of battery. For high power load financially, it is not suitable because of two conversions the maintenance cost of battery has become too high.

\section{E.Compensating power devices}

The compensating custom power devices are used for active filtering, load balancing, and power factor improvement voltage regulating (sag / swell). These devices are mainly three types: static shunt compensator, series and hybrid compensator. These are also called as DSTATCOM, DVR and UPQC respectively.

\section{VI.COMPENSATING DEVICES IN COMBINATION}

A. Distribution Static Compensator (DSTATCOM). DSTATCOM is a Voltage source inverter (VSI) based static compensator device (STATCOM, FACTS controller ) applied to maintain bus voltage sags at the required level by supplying or receiving of reactive power in the distribution system. It is connected in shunt with distribution feeder with the help of coupling transformer. [5]The DSTATCOM consists of a VSI, dc energy storage device, an ac filter and coupling transformer. The operating principle of DSTATCOM that it continuously monitors the load voltages and currents, determines the amount of compensation required by distribution system for a verity of disturbances. In this scheme the active power flow is controlled by the angle between the ac system and VSI voltages, the reactive power flow is controlled by the difference between the magnitudes of these voltages. The DSTATCOM operates in both current and voltage control modes.

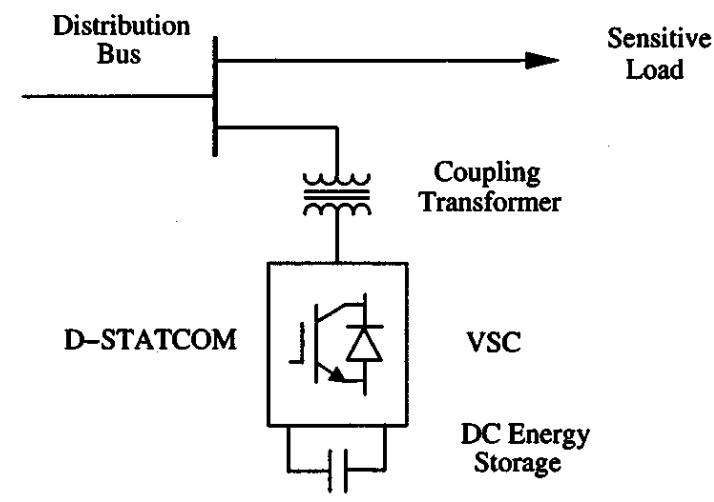

Fig.4 Schematic diagram of D STATCOM [6]

Fig. 3 shows the schematic representation of the DSTATCOM. The VSC converts the dc voltage across the storage device into a set of three-phase ac output voltages. These voltages are in phase and coupled with the ac system through the reactance of the coupling transformer. Suitable adjustment of the phase and magnitude of the DSTATCOM output voltages allows effective control of active and reactive power exchanges between the DSTATCOM and the ac system.

B. Static Series Compensator or (DVR):

The power quality enhancement is very mandatory with the newer generation load equipments, whose performance is very sensitive to power quality disturbances especially with voltage sag, Harmonics and Interruption. The power electronic based power conditioning devices can be the effective solution to enhance the quality of the power supplied to the power distribution system. The series connected Dynamic Voltage Restorer (DVR) is one of the effective solution to mitigate power quality problems in the distribution system. Commercially, static series compensator is known as Dynamic Voltage Restorer (DVR). It is a high-speed switching power electronic controlling device. Also known as series voltage 
booster.DVR is a series connected custom power device, capacitor control simpler. However the size of the dc designed to inject a dynamically controlled voltage in capacitor must be chosen such that it has the ride through magnitude and phase in to distribution line via coupling capability during any transient. The issues involved with

transformer to correct load voltage.

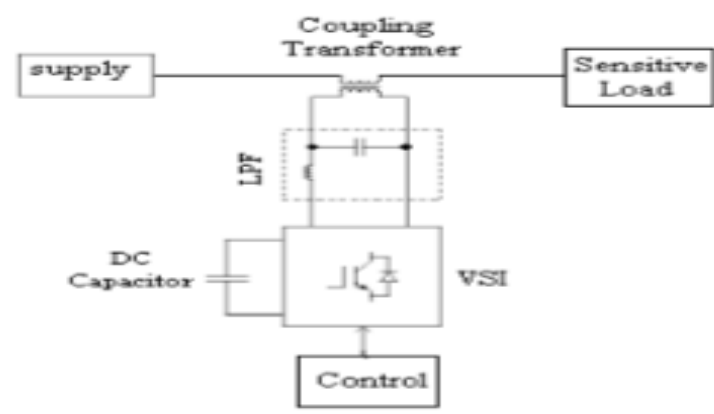

Fig 5 .Static Series Compensator [6]

C. Unified Power Quality Conditioner (UPQC):

A unified power quality conditioner (UPQC) is a device that is similar in construction to a unified power flow conditioner (UPFC) [1]. The UPQC, like a UPFC, employs two voltage source inverters (VSIs) that are connected to a common dc energy storage capacitor. One of these two VSls is connected in series with the ac line while the other is connected in shunt with the same line. A UPFC is employed in a power transmission system to perform shunt and series compensation at the same time. Similarly a UPQC can also perform both the tasks in a power distribution system. However, at this point the similarities in the operating principles of these two devices end. Since a power transmission line generally operates in a balanced, distortion (harmonic) free environment, a UPFC must only provide balanced shunt or series compensation. A power distribution system, on the other hand, may contain unbalance, distortion and even de components. Therefore a UPQC must operate under this environment while providing shunt or series compensation. A UPQC combines a series and a shunt compensator together. Shunt active power filter capability of the current compensation, series active power filter capability of voltage compensation allow mitigation of various power quality problem it can therefore yield the benefits of both these devices.

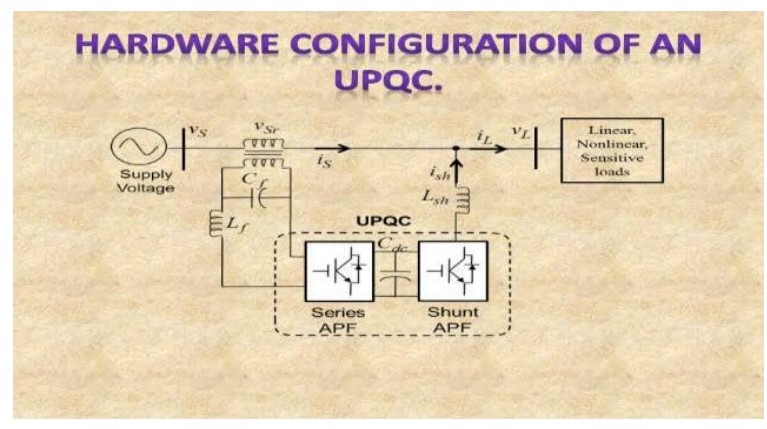

Fig.6 Schematic diagram of UPQC [5]

We have discussed an operation of UPQC in which it can simultaneously correct for the unbalance and distortion in the source voltage and load current. It has been shown that the right-shunt UPQC structure can operate in the zero power injection/absorption modes thereby making the dc size and control of the dc capacitor need to be explored further. A UPQC is an expensive device, as it requires two sets of inverters. However it is much more flexible than any single inverter based device. Thus its full capability must be investigated further. Also new applications of this device must be explored to justify its cost.

\section{VII.CONCLUSION}

In this paper a brief review of custom power devices is given and a comparison is made between them. . Some of the loads can cause significant problems for other loads in their vicinity. It is therefore desirable to compensate for such loads. However, there are economic considerations involved here. For example, whether a load should have a power factor correction depends on the amount of penalty that may be imposed on the customer for not compensating. On the other hand, the loads that cause fluctuations in the supply voltage may have to be compensated to achieve the required level of voltage regulation. The typical loads that cause voltage fluctuations are arc and induction furnaces, very large motors used in rolling mills etc. as they are continuously switched on or off. Again the loads that use power electronic devices such as adjustable speed drives, UPS etc. cause harmonic pollution. With these types of loads, a shunt compensator may be required to reduce the effects of the harmonics on the rest of the system, especially if the size of these loads is very large .These four objectives can be fulfilled by using D STATCOM. The concept of DSTATCOM is similar to STATCOM but in addition DSTATCOM can also used for reactive power compensation [7].

Thus, the most reliable technique is found which can meet the various problems of distribution systems is D STATCOM. D STATCOM can be used in weak supply point connections. In particular these devices can be used both as current compensators to compensate harmonics generated by loads and also as voltage regulators to regulate the voltage of a particular distribution system bus. Now it can be concluded that The DSTATCOM, which is connected in shunt can provide good power quality in both transmission and distribution level.

\section{REFERENCES}

[1] Prabhat Ranjan Sarkar,Abhishek Kashyap,Vineeta Agarwal, "Enhancement in performance of wind energy conversion system including matrix converter" Proc of the Second Intl.Conf.onadvances in Electronics, Electrical and Computer Engineering-EEC 2013.

[2] Prabhat Ranjan Sarkar, Faizan Arif Khan, Israr Ahmad, "Performance Enhancement of Multilevel Inverter in PV System with New Topology" International Journal Of Advance Engineering And Research Development

[3] Arindam ghosh, Gerard Ledwich, "Power quality enhancement using custom power devices" Kluwer Press, 2002

[4] Ankush Sharma, "Review paper on applications of D statcom in distribution system", International Journal of Science and Modern Engineering, ISSN: 2319-6386, Volume-2, Issue-11, and October 2014 
5] Narain. G. Hingorani, "Overview of Custom Power Applications" Hingorani Power Electronics, 26480 Weston Drive, Los Altos Hills, CA 94022

[6] Prafull A. Desale, Vishvadeep J. Dhawale and Ranjeet M. Bandgar, "Brief Review Paper on the Custom Power Devices for Power Quality Improvement" International Journal of Electronic and Electrical Engineering.ISSN 0974-2174 Volume 7, Number 7 (2014), pp. 723-733

[7] M. L. Crow, "Power quality enhancement using custom power devices," IEEE Power and Energy Magazine, vol.2, pp.50, April 2004

[8] M.H. Haque, "Compensation of distribution system voltage sag by DVR and DSTATCOM, " in Proc. IEEE Power Tech., vol.1, pp.5, Sept.2001.

[9] H. Mehta, V. H. Tahiliani, J. E. Sullivan, "Custom Power: an opportunity for energy conversion," in Proc of the International Conference on Electricity Distribution CIRED 1993, pp. 5.23/15.23/6.

[10] A.ElMofty, K. Youssef, "Industrial power quality problems," in Proc. on IEE Int. ConfExhib. on Electricity Distribution, 2001, vol.2, June 2001.

[11] M. H. J. Bollen, "What is power quality?" Electric Power Systems Research, vol.66, pp.5-14, July 2003.

[12] Alexander Domijan, Jr., Alejandro Montenegro, Albert J. F. Keri, Senior Member, IEEE, and Kenneth E. Mattern "Custom Power Devices: An Interaction Study,

\section{BIOGRAPHIES}

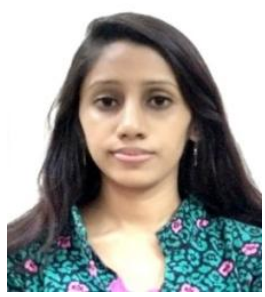

Uzma Aslam was born in Bahraich, Uttar Pradesh, India on 31 December, 1992. She pursued her Bachelor of Technology degree in Electrical and Electronics from Integral University, Lucknow in 2013.Presently she is a student of M.Tech in Instrumentation and Control in the same university. Her topic of interest is Non Conventional Energy Resources, Multi Level Inverter, Converters.

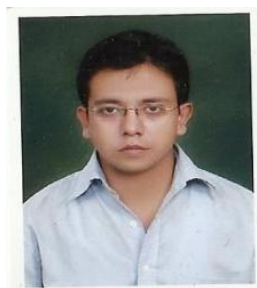

Faizan Arif Khan was born in Tanda, AmbedkarNagar India on 15 Jan, 1986. He graduated from Uttar Pradesh Technical University, Lucknow, India with B. Tech Degree in Electrical and Electronics in 2010.Also he has done Masters of Technology in Electrical Engineering with specialization in Instrumentation \& Control from Integral University Lucknow. He Reviewed and authored several books including EMFT. He is currently an Asst Professor with the dept. of Electrical Engineering, Integral University, Lucknow.

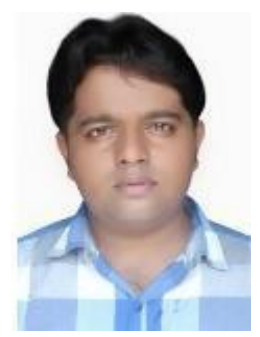

Prabhat Ranjan Sarkar was born in Deoria, India on May 05, 1990. He graduated from Uttar Pradesh Technical University ,Lucknow ,India with B. Tech Degree in Electrical and Electronics in 2011.Also he has done Masters of Technology in Power Electronics and ASIC design at MNIT, Allahabad. He is currently an Asstt Professor with the dept. of Electrical Engineering, Integral University, Lucknow.

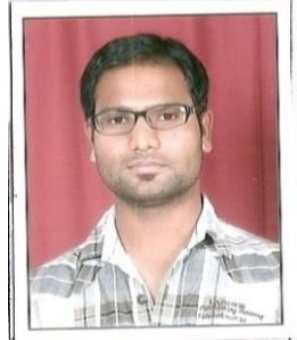

Abu Shoban was born on 07 sep., 1988 in Nanpara, district Bahraich, India. He has passed his B.tech in Electrical and Electronics from Skyline Institute of Engineering and Technology, Greater Noida in 2011.After that he worked as a guest lecturer in Electrical Dept.in Lucknow Polytechnic Lucknow for two years. Currently he is pursuing Masters of Technology in Instrumentation and Control from Integral University, Lucknow. His topic of interests is Machines, Inverters, and Renewable Energy. 